\title{
SURGIMENTO DE SINTOMAS RELATIVOS À PÓS-MODERNIDADE NO CONTEXTO TERAPÊUTICO
}

\section{APPEARANCE OF SYMPTOMS RELATED TO POST-MODERNITY IN THE THERAPEUTIC CONTEXT}

Cristina Gonçalves de Abrantes

Maria Leonor Espinosa Enéas

\begin{abstract}
RESUMO: A presente pesquisa tem o objetivo verificar os principais sintomas que chegam ao processo terapêutico e hipóteses dos pacientes e profissionais sobre possíveis relações com o excesso de atividades e exigência de alto desempenho. Para isso foram feitas cinco entrevistas semiestruturadas, com psicoterapeutas clínicos da abordagem psicodinâmica com pelo menos sete anos de formação. Os dados coletados atingiram o critério de saturação e foram tratados pela análise de conteúdo, baseadas na categorização dos temas surgidos e discutidos à luz da literatura. Foram encontradas oito categorias, descritas na pesquisa. Pôde-se constatar que o período atual se caracteriza pela fluidez da vida em seus mais diversos aspectos, além da necessidade de produção constante como uma forma de não encontrar a si mesmo, superficializando gradualmente a complexidade humana. Nesse sentido, a clínica terapêutica, deve ser um lugar de reflexão sobre tal contexto, chegando às formas de se enfrentar e transformar essa lógica de esvaziamento humano. Sugerem-se futuramente pesquisas qualitativas visando o aprofundamento das categorias encontradas.
\end{abstract}

Palavras-chave: Contemporaneidade. Psicologia clínica. Psicoterapia

ABSTRACT: This research aimed to verify the main symptoms that come to the therapeutic process and examine patients' and professionals' hypothesis about possible correlations with over-activity and high-performance requirement. Therefore, five semistructured interviews were carried out with clinical psychotherapists working with psychodynamic approach, undergraduates for seven years least. Collected information met the saturation criterion and it was treated by content analysis based on the categorization of raised issues and discussed based on previous research. There were eight categories. It cold be stated that the current period is characterized by instability and requirement for constant production as a way to not finding oneself, gradually shallowing human complexity. Therefore therapy clinic must be a place to reflect about this context to attain ways to face and change this human empty. Future qualitative researches in the area are suggested.

Keywords: Contemporaneity. Clinical psychology. Psychotherapy.

\section{INTRODUÇÃ̃O}

Educação, Psicologia e Interfaces, v. 2, n. 1, p. 105-120, Janeiro/Abril, 2018.

DOI: 
A pós-modernidade é contextualizada como sendo sem identidade, com hierarquias móveis, diversos estilos misturados, tecnologia e ciência que avançam rapidamente, porém sem rumo, sendo que a identidade individual é como uma mescla de vivências pequenas e fragmentadas, na qual há não crença em valores maiores (religiosos ou pátrios) e prestígio às micrologias cotidianas (SANTOS, 1993). O conceito de saber na pós-modernidade surge como um conjunto de conhecimentos que autoriza a determinado indivíduo, através do atual contexto identitário profissional, emitir juízos de verdade, moral e estética. Não haveria então mais uma metanarrativa que tornasse os discursos aceitos por todas as culturas. Isso causa grandes desconfianças, não sendo mais possível confiar em nenhum discurso plenamente, acabando então com as metanarrativas. Para a civilização ocidental, fundada em ideais como a democracia, a liberdade e os direitos individuais, esse relativismo representaria um sério risco. É por este motivo, que, como parâmetro, surge a eficácia da teoria, o que produziria melhores resultados e atingiria melhor performance, reduzindo assim, o saber científico a seu aspecto industrial e lucrativo (LYOTARD, 2002).

Indivíduos submetidos a esse cenário encontram-se frequentemente com altos índices de estresse e patologias como forma de somatização. Atualmente, muitos estudos são encontrados sobre a temática estresse, seus sintomas, possíveis causas, consequências, alguns índices e sugestões de formas de enfrentamento e prevenção.

São causas do estresse o medo da reprovação, complexidade de escolhas, pensamentos disfuncionais, alteração de contextos e responsabilidades e pressão social. Esta última envolve expectativas e/ou exigências para que a pessoa se comporte de determinada forma. Ela ocorre quando se sentem forçados a acelerar, intensificar ou mudar a direção do próprio comportamento, ou quando se sentem compelidos a melhorar este desempenho (FAGUNDES, DE AQUINO, DE PAULA, 2010).

Este estudo visa verificar os principais sintomas que chegam ao processo terapêutico e as hipóteses dos pacientes e profissionais sobre possíveis relações com o excesso de atividades e exigência de alto desempenho Trata-se de um estudo exploratório sobre um tema pouco abordado.

Dado que este estudo encontrou sintomas que relacionados com o alto de nível de estresse que o indivíduo vivencia em meio ao contexto caótico urbano contemporâneo, contribui-se para os profissionais da área da saúde mental, principalmente psicólogos do

Educação, Psicologia e Interfaces, v. 2, n. 1, p. 105-120, Janeiro/Abril, 2018 DOI: 
contexto clínico, verificando possibilidades de atenuação e estratégias de enfrentamento do estresse, bem como suas consequências. Dessa forma, o profissional pode pensar em formas de amenizar complicações e potencializar a dinâmica psíquica de seu analisando. Foi possível observar em meio a um estudo inicial a possibilidade do contexto caótico da sociedade moderna, no sentido de excessos de compromissos e obrigações, bem como cobranças externas (sociais) e internas (intrapsíquicas) de alto desempenho nos mesmos, afetar as subjetividades das massas contemporâneas, permitindo uma futura prática mais contextualizada em processos terapêuticos e na saúde mental.

Vale ressaltar que muito pouco foi encontrado na literatura acadêmica a respeito dos temas específicos a serem trabalhados nessa pesquisa. Os malefícios pesquisados até o atual momento se referem ao campo social, como o campo do trabalho e saúde por exemplo. Aqui se propõem explorar a intersecção entre o campo psíquico e social, no que diz respeito aos sintomas que surgem no processo terapêtico que podem estar relacionadas com o excesso de atividades presentes no cotidiano do indivíduo, bem como a exigência de alto desempenho nas mesmas. Assim, a presente pesquisa tem o objetivo verificar os principais sintomas que chegam ao processo terapêutico e hipóteses dos pacientes e profissionais sobre possíveis relações com o excesso de atividades e exigência de alto desempenho.

\section{MATERIAL E MÉTODO}

\subsection{Participantes}

A amostra de conveniência foi composta por cinco psicólogos clínicos da abordagem psicodinâmica, a fim de se aprofundar também em aspectos técnico da área. Todos os profissionais atuam clinicamente por pelo menos oito anos, tendo psicologia como primeira formação, exceto um deles. $\mathrm{O}$ fato de o profissional da saúde deter certa experiência garante algum grau de maturidade técnica, teórica e empírica, além de uma possível comparação de contextos e demandas clínicas atuais e passadas. Segue uma breve descrição de cada participante:

Sujeito 1 - Sexo masculino, oito anos de atuação clínica.

Sujeito 2 - Sexo feminino, quarenta e dois anos de atuação clínica.

Sujeito 3 - Sexo feminino, trinta anos de atuação clínica.

Educação, Psicologia e Interfaces, v. 2, n. 1, p. 105-120, Janeiro/Abril, 2018.

DOI: 
Sujeito 4 - Sexo masculino, vinte e quatro anos de atuação clínica.

Sujeito 5 - Sexo feminino, quinze anos de atuação clínica.

\subsection{Instrumentos}

Foram feitas entrevistas semiestruturadas com cinco questões abertas elaboradas pela pesquisadora. Foram questionados quais são os principais sintomas e questões que chegam à clínica psicoterapêutica, a atribuição deles segundo profissionais e pacientes, se houve mudanças do início da atuação profissional para os tempos atuais e os âmbitos da vida humana que seriam mais afetados pelo contexto pós-moderno.

\subsection{Procedimentos para coleta e análise os dados}

Esta pesquisa foi registrada na Plataforma Brasil sob número CAAE: 59047616.1.0000.0084.

As entrevistas foram gravadas e transcritas mediante autorização escrita dos participantes e seu número foi orientado pelo critério de saturação, ou seja, se cessa a coleta de dados quando não surgem mais elementos novos.

Para o tratamento dos dados, foi utilizada análise de conteúdo, na modalidade de análise temática, resultando na definição dos principais conteúdos e temas das respostas dadas pelos participantes (BARDIN, 2004). Para a realização da análise temática, foram adotadas três etapas: a primeira consiste em, após uma leitura exaustiva das informações, agrupar os dados de acordo com as perguntas formuladas e com outros temas surgidos, objetivando destacar e selecionar os aspectos pertinentes e relevantes do estudo.

A segunda etapa foi a exploração do material, em que foram destacados o que mais se havia dito em cada resposta, sendo em seguida, estabelecidas a determinação da frequência destas e a forma como foi colocado. A última etapa foi a de tratamento dos resultados obtidos e interpretação, analisando as categorias e subcategorias à luz dos fundamentos teóricos.

\section{RESULTADOS E DISCUSSÃO}

O texto a seguir baseia-se inteiramente nas falas emergidas durante a entrevista, segundo a visão dos profissionais. A análise identificou oito categorias baseadas no tema da pesquisa e quatro subcategorias.

Educação, Psicologia e Interfaces, v. 2, n. 1, p. 105-120, Janeiro/Abril, 2018 DOI: 


\subsection{Categoria: contextualização da pós-modernidade}

\section{Subcategoria 1 A-Política e Economia:}

De forma macrossocial, o atual sistema político e econômico neoliberal se fortalece quando se atomizam as relações, quando se privatizam os espaços. Então, para a economia se tornar robusta, é necessário que a política se dissolva, e para que isso ocorra, as relações necessariamente devem também se tornar fluidas e atomizadas. Também se sugere que a posse do dinheiro seria o modo moderno de obter a sensação de conforto que, anteriormente, era obtida através da religião. Predomina-se então o prazer pelo consumo em detrimento da posse do dinheiro, substituindo, portanto, o bem-estar em longo prazo pelo imediatismo fugaz, em que o presente substitui o futuro (SIMMEL, 1998).

Dessa forma, surgiu nas entrevistas que quando se tem uma dissolução da política em consequência do esvaziamento dos vínculos afetivos, se gera esse isolamento que é a atomização das relações. Por mais paradoxal que possa ser essa perda na capacidade de julgamento, de percepção, de discernimento, de compreensão, está se deve ao esvaziamento da esfera pública. Como esse indivíduo vive de forma bastante privatizada, há dificuldade de discernimento do que se sente e de quem se é. Então, ao se isolar, passa a não ser mais visto e não ser mais ouvido. Quando isso ocorre, ele vai tendo uma dificuldade de se perceber. Nesta mesma linha de raciocínio, entende-se que no caso da metrópole banalizam-se as diferenças por estarem sempre presentes neste meio, colocando-as em um lugar comum. Nesse espaço, de constantes novidades e estímulos, a diferença passa a ser indiferente, e o outro agora não mais tem lugar, não sendo passível do olhar empático humano.

A meritocracia enquanto ideologia seria, portanto, o valor universal, o critério fundamental e considerado moralmente correto para qualquer tipo de ordenação social, principalmente no que diz respeito à posição socioeconômica dos sujeitos. $\mathrm{O}$ fato de uma sociedade hierarquizar seus membros para determinadas finalidades, partindo de deus talentos pessoais, não faz dessa sociedade igualitária, já que em muitos casos farão essa seleção através dos atributos que cada um tem (sendo que cada indivíduo possui origens e condições diferentes) que nada têm a ver com o mérito ou o esforço de cada um. Devido

Educação, Psicologia e Interfaces, v. 2, n. 1, p. 105-120, Janeiro/Abril, 2018. DOI: 
a essa lógica, o desempenho é entendido mais como o resultado do ambiente e circunstâncias em que os indivíduos operam do que como consequência dos talentos e de forças intrínsecas de cada um. Assim, a posição socioeconômica dos sujeitos, as deficiências estruturais do sistema nacional e as idiossincrasias pessoais e subjetivas são três importantes fatores que corroboram para o posicionamento profissional e status social (Barbosa, 1996).

Subcategoria 1 B-Características produtivistas:

Nesse cenário pós-modermo, surge a necessidade de alta performance, rendimento, eficiência e carga horária de trabalho elevada, sendo isso exigido do indivíduo e havendo essa mesma percepção de ser o melhor em todos os papéis que desempenha. "Só tem uma coisa pior do ponto de vista social que as pessoas ficam mais aflitas de ter muito trabalho, é estar desempregado. As pessoas preferem toda essa exigência, mas estarem trabalhando" (SUJEITO 4).

Essa lógica de excessos, segundo os depoimentos, leva então à exaustão, ao mesmo passo em que não se pode parar, em que o sujeito se encontra em débito continuamente porque precisa competir o tempo todo, à procura de novas realizações, já que não há mais garantias (no sentido de poder ou não ter um emprego após a graduação, a própria estabilidade dentro de instituições ou relacionamentos instituídos historicamente). São por questões como essas que o indivíduo se torna empresário de si mesmo e não há mais fronteiras entre os diversos âmbitos que vivencia (familiar, amoroso, profissional, etc.), pois ele gerencia todas essas questões, sempre com a necessidade de "dar conta de tudo".

Assim, segundo as entrevistas, a voracidade do mercado de trabalho e exigência de se produzir cada vez mais e pensar menos foram aspectos citados como fatores que corroboram para o esgotamento do indivíduo, que acaba acarretando no afastamento de si e das próprias peculiaridades, já que quase toda energia psíquica do sujeito está investida no ato de produzir e desempenhar com excelência. Isso geraria, portanto, uma sociedade com um grande vazio do ponto de vista dos vínculos, político e da linguagem. Esses valores, agora internalizados e difundidos com a própria identidade, passam a ser parâmetros inquestionáveis, e quanto mais se faz, mas se quer fazer.

Educação, Psicologia e Interfaces, v. 2, n. 1, p. 105-120, Janeiro/Abril, 2018 DOI: 
Subcategoria 1 C-Questões Relacionais:

Caracteriza-se essa época com parâmetros de um mundo organizacional, corporativo, utilitário e pragmático, e o discurso da produtividade sai da esfera profissional e vai se disseminando, invadindo outros âmbitos. A esfera das relações, segundo entrevistados, tem sofrido as consequências dessa lógica da produtividade, da competência. Por esse motivo, a maior parte dos pacientes que chegam à clínica não vêm preparados para o insight.

Fico pensando onde está a complexidade humana, então é uma época que as pessoas a meu ver estão se superficializando cada vez mais e superficializando a própria experiência humana, de contato, associada a esse esvaziamento de si que torna a apresentação ou a exposição do sujeito mais simplista (SUJEITO 5).

Há questões relacionais como dificuldades em comunicação, interlocução, diálogo, dificuldade na relação de vínculo, manutenção e estabelecimento de vínculos, dificuldade na consolidação deles, ausência de relações, solidão profunda e isolamento em função da sobrecarga de trabalho (SUJEITO 5).

Os entrevistados alegaram também que essa lógica se insere no contexto familiar, e especialmente na relação de pais e filhos na medida em que os pais reproduzem o modelo que se passa com eles, na mesma lógica de excesso de tarefas (como diversos cursos e atividades extracurriculares), exigindo também excelente desempenho com notas da escola, esportes e arte, entre outros. Hipotetizou-se que a ansiedade gerada por esse contexto, levou a quadros psicopatológicos ou com alguma dificuldade de ajustamento, então o não prestar atenção seria uma defesa para dizer que não aguentam mais. Com isso, os pais delegam muitas funções a outros profissionais, terceirizando o papel de educação e cuidado. Então há um distanciamento afetivo dessa relação, e os pais gratificam essa criança o tempo todo e dão poucos limites. Esse "fazer tudo o tempo todo" acarreta na diminuição para o encontro, para as relações, para o outro.

É nesse sentido que hoje se habita uma linguagem empresarial, administrativa e corporativa, que foi se expandindo e se inserindo em diferentes âmbitos da vida humana. Discorre-se como possibilidades de somatização o suporte precário para a resolução de problemas, falta de controle, interface entre trabalho e família (como os conflitos nas exigências do trabalho e pouco suporte do lar, sentimento de culpa e ressentimento, ausência de vida social e baixa remuneração), monotonia das tarefas, cargas horárias

Educação, Psicologia e Interfaces, v. 2, n. 1, p. 105-120, Janeiro/Abril, 2018. DOI: 
extensas, falta de orientação, relação abusiva, ciclos trabalho-descanso incoerentes, exigência de alta concentração, pressão do tempo para realização de tarefas, conflito de autoridade, motivação deficiente, falta de suporte, pouca oportunidade (Camelo e Angerami, 2008).

\section{Subcategoria 1 D - Linguagem}

Questões voltadas à linguagem foram expostas na medida em que se usa hoje um linguajar concreto, de forma polarizada e maniqueísta, com dificuldade de se narrar o próprio sofrimento, fixando-se basicamente em descrições de sintomas ou em superficialidades de relações. Aparece hoje um sujeito que está empobrecendo do ponto de vista da linguagem simbólica e não do sintoma necessariamente.

Eu estou falando de uma época em que nós estamos nos empobrecendo do ponto de vista das relações e do ponto de vista da compreensão do próprio sofrimento. As pessoas foram perdendo sua capacidade de percepção da realidade, sua capacidade de discernir os próprios afetos e afetos dos outros (SUJEITO 5).

É através da linguagem que se verificam sintomas e como as relações se constituem. O sofrimento no consultório é traduzido hoje em uma linguagem mais superficial, havendo certa dificuldade de simbolização. É nessa perspectiva que o sujeito adere à linguagem do ambiente corporativo, da autoajuda, das fórmulas prontas, formando uma sociedade cada vez mais "idiotizada", com uma compreensão banal de si e do mundo, e é exatamente esse indivíduo distante de si e do outro que chega ao consultório, sem o menor entendimento do que se passa com ele e com o outro, sem conseguir transformar isso em palavra politizada, que é vivenciada na presença do outro. A legitimação dos saberes só poderia ser local e contextual, e a linguagem só adquiriria sentido quando usada. É por este motivo, que, como parâmetro, surge a eficácia da teoria, o que produziria melhores resultados e atingiria melhor performance, reduzindo assim, o saber científico a seu aspecto industrial e lucrativo (Lyotard, 2002).

\subsection{Categoria: sintomas e questões que chegam ao consultório psicoterápico na pós- modernidade}


No que diz respeito aos sintomas e questões mais encontrados nos consultórios de psicoterapia atualmente, de forma unânime, em decorrência do contexto descrito, surgiram transtornos relacionados à ansiedade, tipos de depressão (inclusive infantil), comportamentos obsessivos compulsivos, quadros fóbicos de forma geral (principalmente pânico) e dependência química.

Ele vem aí com queixa de depressão e eu não vejo desta forma, vejo muito mais uma lógica obsessiva relacionada à alta performance, nesse mega superego e que aparece com uma falta de vitalidade porque está sempre devendo e sempre falta alguma coisa (SUJEITO 1).

Em crianças há diversos casos de hiperatividade e déficit de atenção. Esses quadros foram traduzidos pelos profissionais como formas de tentativas de saída da lógica atual exacerbadamente produtivista através, por exemplo, do embotamento psíquico, de se evitar determinados estímulos, ou da busca pelo princípio do prazer imediato. Eles se questionam se tais indicadores não estariam atrelados a um posicionamento de resistência e uma resposta de "não dar conta" do que se é exigido, afinal reduz ou cessa-se a produção, tanto por falência do corpo como afetiva. Ressaltou-se também que essas questões aparecem com novas roupagens, pois o mal-estar seria o mesmo, que é o malestar na civilização, embora, segundo alguns psicólogos, o quantum de sofrimento psíquico está maior do que há algumas décadas.

Além disso, não poderia ser negligenciada a singularidade de cada caso, e a variabilidade segundo o momento histórico, tipo de público, classe socioeconômica, faixa etária, entre outros. Os aspectos mencionados também estariam necessariamente atrelados a questões existenciais relacionadas com o sofrimento humano e como lidar com uma série de fatores, dentre elas as exigências de um mundo produtivista.

\subsection{Categoria: âmbitos da vida humana mais afetados na pós-modernidade}

Os âmbitos da vida humana mais afetados nesse contexto pós-moderno são o afetivo-relacional e o produtivo. Sobre o primeiro, há dificuldades de estabelecer e manter vínculos, desenvolver relações mais profundas, de se compreender as questões e dialogar com o outro, um desentendimento de parâmetros para compreender a perspectiva do outro e do que está sendo dito nessa relação dentro de um contexto individualista. O segundo aparece com uma dificuldade na adaptação do mundo corporativista, sendo que no próprio

Educação, Psicologia e Interfaces, v. 2, n. 1, p. 105-120, Janeiro/Abril, 2018.

DOI: 
setting terapêutico, termos empresariais como "habilidades, competências e conquistas" são verbalizados.

O fato de viver em um contexto social identitário a partir da função/profissão exercida acaba acarretando na alta relevância disso para o sujeito contemporâneo, também pautado nessa lógica de desempenho e de estar sempre em débito com alguma questão, de sempre ter que estar melhor. Outro ponto discutido foi o fato da lógica produtivista ser transposta para outros contextos, que não somente o profissional, em uma exigência contínua de alto desempenho para qualquer função ou papel exercido pelo indivíduo. Então, há necessidade de se desempenhar absolutamente bem em âmbitos sexuais, interpessoais, intelectuais, maternais/paternais, atenção à própria saúde, beleza física, entre outros.

\subsection{Categoria: alterações sintomáticas em decorrência do tempo}

Pensando nas alterações por decorrência do tempo, do tipo de sintoma ou questão que se chega à psicoterapia, alguns profissionais com mais de 20 anos de atuação percebem que há bastante similaridade nos diagnósticos formados, mas com uma variação ambiental altíssima. Hoje há muitas queixas atreladas à vida acelerada, a correria e multitarefas, acarretando em dificuldade de concentração e fobias e não em formas de neurose que traziam certa dificuldade de adaptação e algum prejuízo no cotidiano, como décadas atrás.

A questão da tecnologia e internet foi exposta como causadora (embora não única) dessa transformação de ritmo, que criaria ansiedade e fobias pela exigência de se estar conectados a muitas coisas e a nada ao mesmo tempo. "As pessoas têm que ficar conectadas em muitas coisas, mas acabam muito longe de si. Não estou dizendo que isso é ruim, mas cria uma rapidez que eu não sei se a gente consegue acompanhar". (SUJEITO 3).

O conceito de liquidez é inerente à modernidade, no sentido do estado de descontrole do mundo, opondo-se a época anterior, "modernidade sólida", em que havia certa exigência para se seguir uma conduta e modo de vida, que era o núcleo da ideia de povo e nação, eliminando qualquer possibilidade de ambivalência através do método científico positivista. Na pós-modernidade, haveria então mobilidade, liquidez das relações e aceleração do ritmo de vida (BAUMAN, 1999).

Educação, Psicologia e Interfaces, v. 2, n. 1, p. 105-120, Janeiro/Abril, 2018

DOI: 
Atualmente vive-se o individualismo qualitativo, diferente dos ideais iluministas que pregavam a liberdade e igualdade para todos. Por esse viés há o conceito maior de indivíduo como único e específico, exigindo que os indivíduos se distingam de outros através dos próprios recursos (SIMMEL, 1998).

Vale ressaltar que muitas características que para Bauman, só se tornaram relevantes na modernidade líquida (depois da pós-modernidade sólida, constituída principalmente nas últimas décadas do século XX pautando-se na ideia de globalização, incerteza e descontrole), para Simmel sempre estiveram presentes na modernidade desde o início do século XX, já caracterizando tal período por sua fluidez.

Além disso, constatou-se nas entrevistas, que atualmente há uma maior tranquilidade das pessoas de se estar no espaço de psicoterapia e análise, sugerindo um retraimento da estigmatização desse espaço voltado para pessoas "loucas" ou "desajustadas".

\subsection{Categoria: formação de diagnósticos psicopatológicos na pós-modernidade}

Em relação à formação de diagnósticos, foi dito que alguns pacientes chegam encaminhados por psiquiatras já com uso de medicação, e muitas vezes esses foram dados equivocadamente, por estarem atrelados a questões contextuais e não necessariamente psicopatológicas. Há outros pacientes que se autodiagnosticam (de forma errônea quase sempre) porque leram em algum lugar, viram na televisão ou um amigo falou sobre aquilo, indicando que esses termos estão presentes no senso comum, havendo certa banalização desses quadros médicos. Também foi constatada uma procura cada vez maior da medicalização para crianças com faixas etárias cada vez menores.

Por fim, há um novo movimento de psiquiatras que encaminham para psicólogos por entenderem que o caso não se enquadra em questões médicas, podendo haver ou não certa resistência dos pacientes nesse caso. Os entrevistados se declararam ponderados no que diz respeito ao uso da medicação e faziam o encaminhamento para o modelo médico em casos de real necessidade.

3.6 Categoria: percepção do paciente na psicoterapia sobre a possível relação de seu sofrimento com o contexto em que está inserido

Educação, Psicologia e Interfaces, v. 2, n. 1, p. 105-120, Janeiro/Abril, 2018.

DOI: 
Em relação à percepção do paciente sobre a forma como é inserido nesse contexto, constatou-se que alguns conseguem fazer essa associação e outros não. "Esse simbolismo vai sendo dissolvido e transformado numa linguagem de resultados imediatos, e quando o tempo não é vivido em sua complexidade, o sujeito fica atrás de fórmulas, não faz essa associação” (SUJEITO 5). Isso depende principalmente da capacidade de simbolização do indivíduo, através da palavra potente que alcança além do próprio universo psíquico.

A escolarização ou questões cognitivas foram associadas a essa condição na medida exclusiva em que é necessário conhecer, aproximar-se do fenômeno para enfrentá-lo. Além disso, foi ressaltado que para o indivíduo constatar que não deseja se submeter de maneira passiva a tudo que lhe é solicitado, muitas vezes após algum tempo de análise, ele costuma procurar alternativas que amenizem isso, tornando tal situação um pouco mais confortável. No entanto, há um grande número de pessoas com grande dificuldade de ligar o próprio mundo com tudo que os envolve.

\subsection{Categoria: relação de responsabilização do próprio sofrimento segundo o paciente de psicoterapia}

No que diz respeito à relação de responsabilização, percebe-se que os pacientes procuram a análise de forma geral, com a perspectiva de que há algo errado consigo na medida em que têm dificuldade de adaptar-se ao contexto, sempre em um movimento contínuo de competir e comparar-se, "tornando-os vítima de um estresse exagerado, que gera ansiedade e angústia e que leva ao adoecimento psíquico" (Sujeito 2).

Ocorre em muitos casos um primeiro momento projetivo de culpabilização do outro, coerentemente com a perspectiva da contemporaneidade de se atribuir ao outro ou a algum fenômeno, como um diagnóstico médico, por exemplo, a relação direta de culpa. "Antigamente as pessoas diziam que tinham um emprego que os fazia mal, até porque tinham um chefe que os perseguia. Agora dizem que tem um chefe que causou a sua doença” (Sujeito 2).

Neste mesmo sentido, acredita-se que a grande diferença entre os indivíduos que adoecem mais ou menos facilmente, com mais ou menos intensidade, não se deve necessariamente ao nível de exposição aos estressores, nem às características de inserção social, mas, sobretudo, com as maneiras de lidar e atribuir significados às próprias

Educação, Psicologia e Interfaces, v. 2, n. 1, p. 105-120, Janeiro/Abril, 2018 DOI: 
vivências, visto que a capacidade adaptativa, em sua perspectiva psicossocial, assume importante significação (FARO; PEREIRA, 2013).

\subsection{Categoria: Exigência e papel da clínica psicoterápica na pós-modernidade}

Finalmente, não pôde deixar de se notar que da mesma forma que é exigido dos indivíduos contemporâneos o foco em resultado de forma imediata, essa mesma cobrança ocorre em relação à clínica psicoterapêutica. Exigem-se então resultados pragmáticos, utilitários e em curto prazo. Procuras por menos vezes na semana e até por linhas específicas da psicologia estão aumentando, uma vez que alguns psiquiatras afirmam que determinado tipo de terapia "tira" tal sintoma.

Alguns entrevistados afirmaram fazer questão de proteger a psicoterapia desse espírito puramente utilitário para que pudesse haver esse encontro com o próprio eu. "Não podemos só manter essas relações de poder, temos que poder resistir, e a clínica pode ser esse dispositivo de resistência, não de apenas conformismo e adaptação, problematizando essa lógica de exigência de alto desempenho” (SUJEITO 1).

Mediante tal contexto, ao se questionar qual seria o principal papel da clínica psicoterápica na atualidade, surgiram afirmações embasadas na investigação e aprofundamento do próprio mundo do paciente, permitindo-se questionar quais seriam os próprios desejos, seu lugar no mundo, identificar que se sofre em determinado contexto e questionar as causas desse sofrer, construindo e pensando novas formas de cuidado e empoderamento humano, encontrando seu próprio sentido (sabendo que poderia ser contrariado e criticado). Isso ocorreria através de um apontamento, não didático, mas principalmente através do vínculo terapeuta-paciente, do contexto em que ele está inserido, articulando estes mundos através da potencialização da palavra, que muitas vezes se encontra bastante esvaziada, trazendo uma linguagem que possa aprofundar essa compreensão.

\section{CONCLUSÕES}

O conteúdo das entrevistas gerou oito categorias, sendo que a primeira se dividiu em quatro subcategorias. Baseou-se, primeiramente, na contextualização da pósmodernidade e atribuição dos sintomas e questões que chegam à psicoterapia, discorrendo

Educação, Psicologia e Interfaces, v. 2, n. 1, p. 105-120, Janeiro/Abril, 2018. DOI: 
o atual contexto econômico e social, e como o neoliberalismo produz valores meritocráticos, do marketing de si, da competitividade, entre outros. As características produtivistas da sociedade atual também foram ressaltadas na medida em o sujeito inserido neste contexto transpõe ritmo e necessidade de alto desempenho industrial/corporativo para outros âmbitos da vida, como familiar, sexual, educacional e lazer. As questões relacionais mostraram o movimento na direção da superficialização das relações, pautadas agora em aparências e papéis, dificultando o estabelecimento de vínculos e provocando o esvaziamento dos indivíduos. É justamente por essa lógica, que a linguagem se encontra em um formato bastante simplista e polarizado, fragilizando relações, dificultando diálogos e encontro consigo mesmo.

Em relação aos sintomas de maior frequência no contexto terapêutico, foram mencionados transtornos relacionados à ansiedade, depressão, comportamentos obsessivos compulsivos, quadros fóbicos, dependência química, déficit de atenção e hiperatividade em crianças, sendo os âmbitos relacionais e produtivos os mais afetados na pós-modernidade. Foi enfatizada a existência de uma banalização de diagnósticos, transposta para o senso-comum, que se "rotula" cada vez mais com determinada psicopatologia, além do crescimento extenuante da medicalização diante de comportamentos que podem ser tidos como decorrência do contexto pós-moderno. Como consequência, constatou-se que os indivíduos procuram responsabilizar determinado “desajuste emocional” ou um fator específico, reduzindo a complexidade da situação, ou a si mesmo, no sentido de suportar o que acreditam ser necessário. São apenas alguns sujeitos que fazem a associação de seu sofrimento com o contexto em que vivem, muitas vezes, depois de um tempo de análise.

Finalmente, as características pós-modernas acabam se atrelando também ao contexto psicoterapêutico, na medida em que também nele é exigido que a clínica apresente resultados rápidos, imediatos e concretos. Alguns profissionais afirmaram trabalhar com o intuito de proteger a clínica deste contexto puramente utilitarista, fazendo este espaço também como dispositivo de resistência e questionamento, pensando novas formas de cuidado e empoderamento humano.

Além disso, observou-se que a clínica psicoterapêutica pode ser um dispositivo de reflexão sobre esse contexto, chegando a formas de se enfrentar e transformar essa lógica de esvaziamento humano.

Educação, Psicologia e Interfaces, v. 2, n. 1, p. 105-120, Janeiro/Abril, 2018 DOI: 
Novas pesquisas podem aprofundar os aspectos observados neste estudo, além de investigar como profissionais ligados a outras vertentes teóricas percebem e trabalham nas condições atuais.

\section{REFERÊNCIAS BIBLIOGRÁFICAS}

BARBOSA, L.. Meritocracia à brasileira: o que é desempenho no Brasil? Revista do Servidor Público 3; 58 - 72, 1996.

BARDIN, L. Análise de conteúdo. $3^{\text {a }}$ ed. Lisboa: Trad., 2004

BAUMAN, Z.. Modernidade e Ambivalência. 1ª ed. Rio de Janeiro: J. Zahar Ed., 1999;

CAMELO, S. H. H.; ANGERAMI, E. L. S. (2008). Riscos psicossociais no trabalho que podem levar ao estresse: uma análise da literatura. Ciência, Cuidado e Saúde, 7(2), 234-240, 2008.

FAGUNDES, P. R.; DE AQUINO, M. G.; DE PAULA, A. V.. Pré-vestibulandos: Percepção do estresse em jovens formandos do ensino médio. Akrópolis-Revista de Ciências Humanas da UNIPAR, 18(1), 57-69, 2010.

FARO, A.; PEREIRA, M. E. Estresse: Revisão narrativa da evolução conceitual, perspetivas teóricas e metodológicas. Psicologia, Saúde \& Doenças, 14(1), 78-100, 2013.

LYOTARD, J. F. A condição pós-moderna. 1ºd. São Paulo: J. Olympio, 2002.

SANTOS, M.. A aceleração contemporânea: tempo mundo e espaço mundo. Boletín Geográfico, (19), 15-22, 1993.

SIMMEL, G. Dinheiro na cultura moderna. In: SOUZA, Jessé; OËLZE, B. (Orgs.)

Simmel e a Modernidade. Brasília, Editora UNB, pp 23-42, 1998.

\section{Credenciais das autoras}

ABRANTES, Cristina Gonçalves de. Possui graduação em Psicologia pela Universidade Presbiteriana Mackenzie.

ENÉAS, Maria Leonor Espinosa. Possui graduação em Psicologia pela Universidade de São Paulo (1980), mestrado em Psicologia pela PUC Campinas (1993) e doutorado em Psicologia pela PUC Campinas (1999). Atualmente é professora da Universidade Presbiteriana Mackenzie.

Educação, Psicologia e Interfaces, v. 2, n. 1, p. 105-120, Janeiro/Abril, 2018.

DOI: 
Como citar este artigo (Formato ABNT): ABRANTES, Cristina Gonçalves de; ENÉAS, Maria Leonor Espinosa. Surgimento de sintomas relativos à pós-modernidade no contexto terapêutico. Educação, Psicologia e Interfaces, v. 2, n.1, p.105-120, 2018.

Recebido: 02/02/2018.

Aceito: 20/03/2018. 